\title{
An ocean modelling and assimilation guide to using GOCE geoid products
}

\author{
K. Haines ${ }^{1}$, J. A. Johannessen ${ }^{2}$, P. Knudsen ${ }^{3}$, D. Lea ${ }^{4}$, M.-H. Rio ${ }^{5}$, L. Bertino ${ }^{2}$, F. Davidson ${ }^{6}$, and F. Hernandez \\ ${ }^{1}$ Environmental Systems Science Centre, Harry Pitt Bld, 3 Earley Gate, Reading University, Reading RG6 6AL, UK \\ ${ }^{2}$ NERSC, Nansen Environmental and Remote Sensing Centre, Thormøhlensgt. 47, 5006 Bergen, Norway \\ ${ }^{3}$ Technical University of Denmark, National Space Institute, Department for Geodesy, Juliane Maries Vej 30, \\ 2100 Copenhagen, Denmark \\ ${ }^{4}$ Met Office, FitzRoy Road, Exeter EX1 3PB, UK \\ ${ }^{5}$ Collecte Localisation Satellites, CLS-DOS, 8-10 rue Hermes, Parc Technologique du Canal, Ramonville St Agne, \\ 31520, France \\ ${ }^{6}$ DFO-NAFC MPO-NAFC, 80 East White Hills Rd, P.O. Box 5667, St. John's, NL A1C 5X1, Canada \\ ${ }^{7}$ Mercator Ocean/IRD, 8-10 rue Hermes, Parc Technologique du Canal, Ramonville St Agne, 31520, France
}

Received: 7 October 2010 - Published in Ocean Sci. Discuss.: 5 November 2010

Revised: 7 February 2011 - Accepted: 12 February 2011 - Published: 23 February 2011

\begin{abstract}
We review the procedures and challenges that must be considered when using geoid data derived from the Gravity and steady-state Ocean Circulation Explorer (GOCE) mission in order to constrain the circulation and water mass representation in an ocean general circulation model. It covers the combination of the geoid information with time-mean sea level information derived from satellite altimeter data, to construct a mean dynamic topography (MDT), and considers how this complements the timevarying sea level anomaly, also available from the satellite altimeter. We particularly consider the compatibility of these different fields in their spatial scale content, their temporal representation, and in their error covariances. These considerations are very important when the resulting data are to be used to estimate ocean circulation and its corresponding errors.

We describe the further steps needed for assimilating the resulting dynamic topography information into an ocean circulation model using three different operational forecasting and data assimilation systems. We look at methods used for assimilating altimeter anomaly data in the absence of a suitable geoid, and then discuss different approaches which have been tried for assimilating the additional geoid information. We review the problems that have been encountered and the lessons learned in order the help future users. Finally we
\end{abstract}

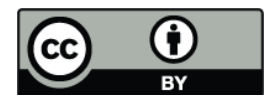

Correspondence to: $\mathrm{K}$. Haines

(k.haines@ reading.ac.uk) present some results from the use of GRACE geoid information in the operational oceanography community and discuss the future potential gains that may be obtained from a new GOCE geoid.

\section{Introduction}

During the late eighties as satellite altimeter data became available globally over longer periods of time, huge efforts were made in the geodetic community to process global data sets to give joint analyses of geoid and ocean dynamic topography, along with a reduction in satellite orbit errors (Wagner, 1986; Engelis and Knudsen, 1989; Denker and Rapp, 1990; Marsh et al., 1990; Nerem et al., 1990). The quality of the available data were not sufficient to recover the details of the general ocean circulation, however the very large scales $(>5000 \mathrm{~km})$ of the dynamic topography could be recovered and compared with the early oceanographic results obtained from hydrographic data, e.g. Levitus and Boyer (1994). Already at this time the importance of consistency between the reference ellipsoids, as well as the role of the permanent tidal correction were identified as issues. Meanwhile in local regions marine gravity data obtained from ships could increase knowledge of the gravity field, and thereby the geoid. Such local data in combination with altimeter data did yield more accurate estimates and details of the dynamic topography (Wunsch and Zlotnicki, 1984; Mazzega and Houry,

Published by Copernicus Publications on behalf of the European Geosciences Union. 
1989; and Knudsen, 1991, 1992). Much more recently the release of satellite gravity data from the GRACE mission and the launch of the ESA Gravity and steady-state Ocean Circulation Explorer (GOCE) satellite on 17 March 2009 are now starting to provide a more accurate global picture of the Earth's gravity field than ever before, which will allow new details of the ocean dynamic topography to be detected (Johannessen et al., 2003), including small spatial scales and even temporal variability of the ocean geoid due to ocean mass changes, e.g. Chambers et al. (2007).

The basic definition of the ocean dynamic topography is simply the difference between the sea surface height and the constant geopotential reference surface called the geoid. Simultaneously the dynamic topography may be considered as a streamfunction for the ocean circulation at the ocean surface because the sea level slopes relative to the geopotential surface allow calculation of surface ocean currents. Oceanographers have become very familiar with the uses of satellite altimeter data over the last $17 \mathrm{yr}$, which determine variability in sea level slopes and ocean currents, but are much less familiar with the geodetic information, required to determine absolute ocean currents, that gravity satellites will provide. A recent paper by Hughes and Bingham (2008) has sought to partly redress this, and covers many of the subtleties of doing calculations with global geodetic information. In addition the EU FP6 project GOCINA brought together a small consortium of geodesists and oceanographers with the objective to develop a common understanding of the geodesy and oceanographic needs, in order to prepare to get the maximum information out of the new data from GOCE (Knudsen et al., 2006a, b; Knudsen and the GOCINA Team, 2007), which aims to map the geoid at spatial scales of around $100 \mathrm{~km}$ with $1-2 \mathrm{~cm}$ accuracy. There is an important new opportunity with the GOCE mission that will for the first time provide error covariance information on the gravity field down to spatial scales of $100 \mathrm{~km}$. This will allow the impact and constraints of the new gravity anomalies and geoid information on the estimates of ocean circulation to be rigorously assessed.

The purpose of this paper is to further advance mutual understanding between the geodesy and oceanography communities. The Hughes and Bingham (2008) paper contains material which will be largely familiar to the satellite geodesy community but was not previously accessible to oceanographers. Among others, that paper addresses methods for producing a mean dynamic topography from the gravity and altimeter data. However, it stops short of discussing how the mean dynamic topography (MDT) will be used by the oceanography community or how the errors in the MDT would be estimated and used. This paper starts with a brief summary of consistency checks between geodesy and altimeter data, followed by further discussion on calculating the MDT, including the treatment of commission and omission errors. The uses of satellite gravity data within oceanography is then discussed, and should help to explain to the geodesy community the subtleties encountered for ocean circulation studies. The paper draws heavily on the experiences from European consortium projects GOCINA, GOCINO and GUT preparing for the GOCE mission, and seeks to highlight the major use cases that have been developed over the last few years. It then proceeds with discussion of the methods oceanographers use to determine ocean circulation, particularly through assimilation into ocean models. In so doing, it gives examples from the operational oceanography community showing how new MDT data are being used now to constrain ocean forecasting models. As such the paper should stimulate further cross-disciplinary research in geodesy and oceanography, and trigger interest in the oceanographic community to contribute to the challenging task of validation of the GOCE derived geoid and MDT, both on global and regional scales.

\section{Construction of the MDT}

Taking the common viewpoint that the dynamic topography is the height difference between the Mean Sea Surface (MSS, from a radar altimeter) and the geoid surface determined geodetically, the ability to form a consistent difference between these two fields and construct the Mean Dynamic Topography (MDT) is at the heart of oceanography applications.

\subsection{Compatibility of altimeter and geoid data}

The practical task of computing a MDT from a MSS and a geoid is conceptually very simple, however there are some issues that must be considered in order to obtain a good MDT product.

- The MSS and the geoid must be represented relative to the same reference ellipsoid.

- The permanent effects of earth tides are handled consistently. The geodetic "mean-tide" system, including the permanent sun and moon gravitation within the geoid, must be used as it will be affecting the altimetry. The ESA GOCE HPF geoid represents the "tide-free" system which removes the indirect effects of the permanent deformation of the Earth due to the sun/moon gravity.

- The altimetry used for the MSS in the MDT calculation must have the same corrections applied as for the computation of the sea level anomalies. If new inverse barometer corrections e.g. Carrère et al. (2003), are applied to the altimeter anomalies then the same corrections should be applied to the MSS.

- Most ocean circulation models do not represent atmospheric pressure forcing, necessitating the removal of this effect from the observational data prior to comparison or assimilation. 


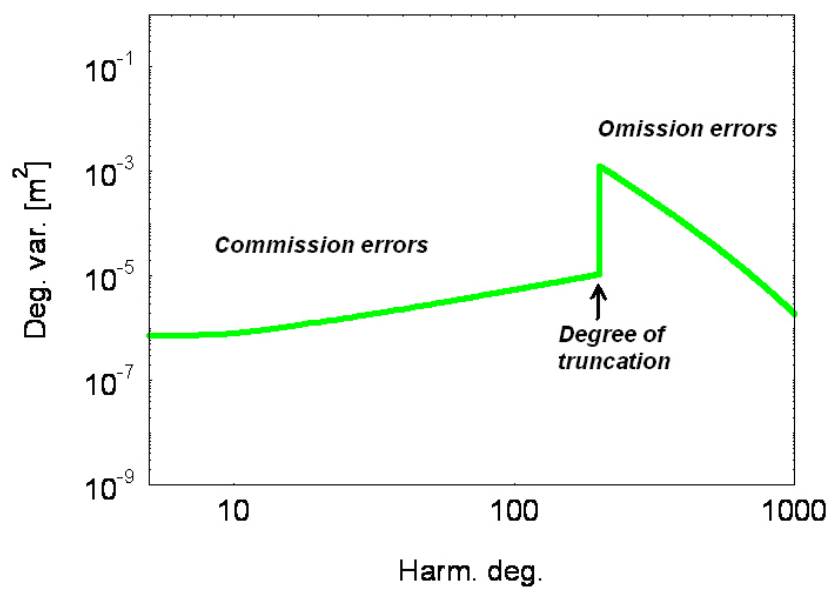

Fig. 1. Error degree variances of the geoid after a GOCE geoid model has been removed. The error spectrum consist of GOCE model errors up to degree 200 (the commission errors) and full geoid signal above degree 200 (the omission errors).

- The MSS (and any derived MDT) will be based on a particular time period and it should be recalled that the ocean will have variable circulation on all timescales. When comparing a satellite based MDT with a model solution only the same time periods should be compared. Altimeter data may be used to make time period corrections from 1992 onward, e.g. Bingham and Haines (2006).

\subsection{Scales of variability and errors in the sea level and the geoid}

The geoid and the sea surface have large variations in height $(\sim \pm 100 \mathrm{~m})$ relative to the reference ellipsoid. The ocean dynamic topography which is the difference between these is a small residual which varies only by $\sim \pm 1 \mathrm{~m}$. It is therefore vital to handle the uncertainties and errors in both the MSS and the geoid effectively to get a useful dynamic topography result. This differencing is complicated by the fact that global geoid models are usually represented with spherical harmonic coefficients, while altimeter sea levels are measured in physical space over ocean basins alone. The MSS is relatively well determined down to small spatial scales, but only defined over the oceans. The geoid is more poorly known especially at small spatial scales, leading to the practice of early truncation of the spherical harmonic expansion used to describe it. Furthermore, errors in the coefficients have a larger impact at higher spherical degrees where the gravity signal is smaller. Those errors in the geoid caused by errors in the coefficients are often referred to as commission errors while the error due to truncation of the coefficient series are referred to as omission errors (see Fig. 1). Both types of errors limit the accuracy with which the dynamic topography can be calculated.
Some global geoid models are derived using a combination of gravity field related information and also gravity anomalies derived from satellite altimetry. Examples of such combination models are EGM96, EIGEN-GL05C, and EGM08. These models may contain a representation of the geoid up to a rather high harmonic degree; however only at lower harmonic degrees does the geoid represents the pure gravity field. At higher degrees the geoid model will be based on information derived from altimetry, where the geoid model will be fitting the sea surface (usually an a-priori MDT is used in the computation). Naturally, the MDT associated with those higher harmonic degrees cannot be derived from such geoid models.

\subsection{Strategy for differencing}

It is easy to fail to use all of the useful geoid accuracy when calculating the MDT because of the need to obtain a smooth solution. The separation of the MDT from the MSS and the geoid may be carried out in either the physical space domain, where the MSS is usually represented, or in the spectral domain where global geoid models are usually represented. Each methodology has issues where care is needed. The "physical space domain methods" where the geoid is calculated in physical space from the set of harmonic coefficients and subtracted from the MSS, require a proper filtering of the differences to eliminate the short scale geoid signal present in the MSS to obtain the MDT. To achieve this, simple to more complex filters can be used. Jayne (2006) applied a Hamming window smoother while Vianna and Menezes (2010) developed an adaptive filter, based on principal components analysis techniques, in order to remove as much noise as possible while minimizing signal attenuation. The "spectral domain methods" require that the MSS be expanded into spherical harmonics to carry out the differencing using the coefficients of the geoid and the MSS. The fundamental problem in applying spectral domain methods is that the MSS and MDT are not defined over land, hence hampering the global spherical harmonic expansion.

Benveniste et al. (2007) describes several procedures for determining the MDT, applying both physical space domain and spectral domain methodologies. The physical space domain filtering should account for the geoid omission errors which must be removed from the MSS in order to "match" the information content from the 2 fields. Failure to do so properly leads to errors that appear at scales where the geoid model harmonic expansion has been truncated. Bingham et al. (2008) give examples of this and then point out that the spectral domain approach has the advantage that it can seek deliberately to modify and match the omission errors of the MSS towards those of the geoid, because it is the geoid that defines the limiting resolution in spectral space. By matching the omission errors well in the spectral domain, only the variability of the much smaller MDT needs to be converted back into physical space. Problems with the spectral 
approach then focus on smoothly extending the MSS to a global field before generating the spherical harmonic expansion (the MSS is not well known in polar seas and is not defined at all over land).

An intuitively satisfying solution is to start with (MSS$\mathrm{MDT}_{\mathrm{b}}$ ) over the ocean matched to a geoid $\mathrm{d}_{\mathrm{b}}$ over land, where $\mathrm{MDT}_{\mathrm{b}}$ and geoid $\mathrm{b}_{\mathrm{b}}$ are "background" or a-priori estimates of the new geoid and MDT to be calculated. This defines a global background field which, when converted into spherical harmonics and differenced with the new satellite geoid, should leave the smallest and smoothest possible residual corrections to $\mathrm{MDT}_{\mathrm{b}}$. These are then converted back into physical space giving the smallest possible amplitude of Gibbs fringe problems, and so requiring little physical space smoothing before being used to correct $\mathrm{MDT}_{\mathrm{b}}$. This should in principal be the best way of getting the most oceanographic information out of the new geoid from GOCE, but the method requires further sustained research. It is interesting that a similar remove-restore approach to analyzing corrections to an a-priori MDT is often used by geodesists to improve a geoid based on new point gravity measurements, e.g. Hipkin and Hunegnaw (2006). The following section looks at several attempts to obtain MDT information with error estimates based on in situ oceanographic information that can be used in the evaluation of geodetic MDT products.

\section{Mean dynamic topography evaluation}

\subsection{Comparison to independent oceanographic MDT estimates}

Assessing the accuracy (in terms of error variance and covariance) of the ocean Mean Dynamic Topography is a crucial and complex issue. When obtained from the subtraction of an altimetric MSS and a geoid model, error in the MDT depends both on errors in the altimetric MSS (including the errors, poorly known, on the various altimetric corrections) and in the geoid.

Rio and Hernandez (2004) advocate the development of synthetic estimates of the MDT as follows. In-situ ocean measurements made between 1993 and 2007 are used to derive either dynamic topography $h$ or geostrophic velocity $u, v$. The time-dependent components, $h^{\prime}$ or $u^{\prime}, v^{\prime}$, is derived from altimetric Sea Level Anomalies, and subtracted to estimate the Mean Dynamic Topography (or respectively the mean geostrophic circulation).

$\bar{h}_{93-99}=h-h_{1993-1999}^{\prime} \quad \bar{u}_{93-99}=u-u_{1993-1999}^{\prime}$

$\bar{v}_{93-99}=v-v_{1993-1999}^{\prime}$

These synthetic estimates are then compared to the direct estimates of the MDT (MSS minus geoid). The Root Mean Square $\left(\mathrm{RMS}_{1}\right)$ differences between synthetic estimates of the MDT and the direct geoid-based MDT can be written as the sum of different error contributions

$\mathrm{RMS}_{1}^{2}=\varepsilon_{\text {synth }}^{2}+\varepsilon_{\text {MSS }}^{2}+\varepsilon_{\text {geoid }}^{2}+\varepsilon_{\text {om }}^{2}$

$\varepsilon_{\text {MSS }}^{2}$ is the error on the MSS. $\varepsilon_{\text {geoid }}^{2}$ is the error on the geoid (it is assumed that both these errors represent commission errors appropriate to the same resolved scales). $\varepsilon_{\text {synth }}^{2}$ is the synthetic MDT error estimate. $\varepsilon_{\mathrm{om}}^{2}$ is the omission error: it represents the MDT spatial scales contained in the synthetic product but not resolved by the directly derived MDT because of the need to truncate the scales contained in the geoid. One way to deal with the omission error is to filter the synthetic estimates (superscript $\mathrm{f}$ ) to the same scale as the direct MDT (see below for filtering details in Fig. 2), then:

$\mathrm{RMS}_{2}^{2}=\varepsilon_{\text {synth }_{\mathrm{f}}}^{2}+\varepsilon_{\mathrm{MSS}_{\mathrm{f}}}^{2}+\varepsilon_{\text {geoid }_{\mathrm{f}}}^{2}$

The most directly useful oceanographic in-situ data consists of the $15 \mathrm{~m}$ drogued drifting buoy data collected from 1993 to 2007 in the framework of the international WOCE and TOGA Surface Velocity Program, providing 6-hourly velocity measurements (http://www.meds-sdmm.dfo-mpo. gc.ca). To extract only the geostrophic component, the Ekman current was first modelled (Rio and Hernandez, 2004) and removed, and a 3 day low pass filter was applied to remove inertial and tidal currents as well as residual high frequency ageostrophic currents. The $0-1000 \mathrm{~m}$ temperature and salinity hydrographic profiles from the Coriolis database allow dynamic height to be calculated for the same period. These dynamic heights were supplemented with the missing barotropic and deep baroclinic components using the $1000 \mathrm{~m}$ dynamic topography relative to $2000 \mathrm{~m}$ computed by Willis et al. (2008), based on Argo drift velocities and assumed to still be valid for the mean period 1993-1999. At high latitudes, where few ARGO drift measurements are available, the method can fail to recover the full missing components.

Altimeter data is used both in the direct MDT calculation, e.g. the Mean Sea Surface (MSS) CLS01 for the period 1993-1999 (Hernandez and Schaeffer, 2000), and also to remove the time variability from the synthetic MDT, as in Eq. (1). Maps of Sea Level Anomalies (SLA) from AVISO for the period 1993-2007 but relative to the $7 \mathrm{yr}$ mean (19931999), are used. The EIGEN-GL05S geoid model is based on five years of GRACE data, and is available to degree and order 150 spherical harmonics, which is equivalent to a resolution of $133 \mathrm{~km}$.

Figure 2a, $\mathrm{b}$ shows the MDT obtained using the synthetic method described above, unfiltered and filtered at $500 \mathrm{~km}$ resolution, using a Gaussian filter $G(r)=e^{-4\left(\frac{r}{r_{c}}\right)^{2}}$. When using such a spatial filter, $65 \%$ of the spatial scales shorter than $r_{c}$ are removed (90\% of the spatial scales shorter than $r_{c} / 2$ ), etc. Figure 2c, d shows the MDT obtained using the direct method, filtered at $133 \mathrm{~km}$ and $500 \mathrm{~km}$, respectively. The consistency between the synthetic MDT and the direct MDT 
(a)
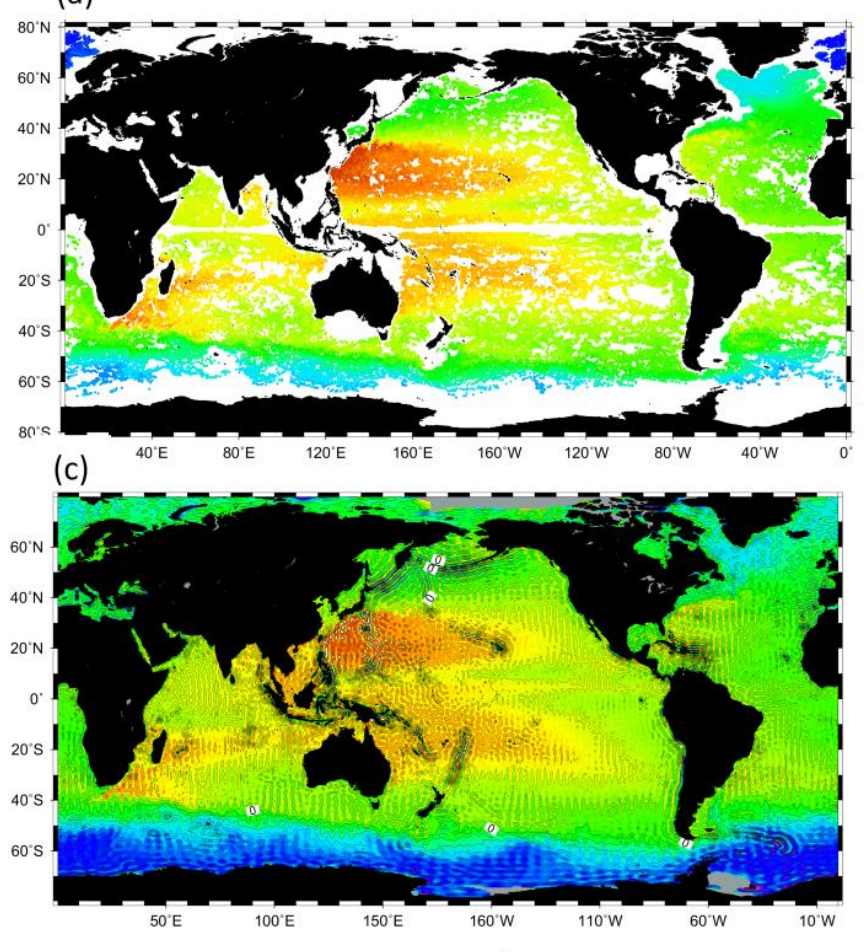

(b)

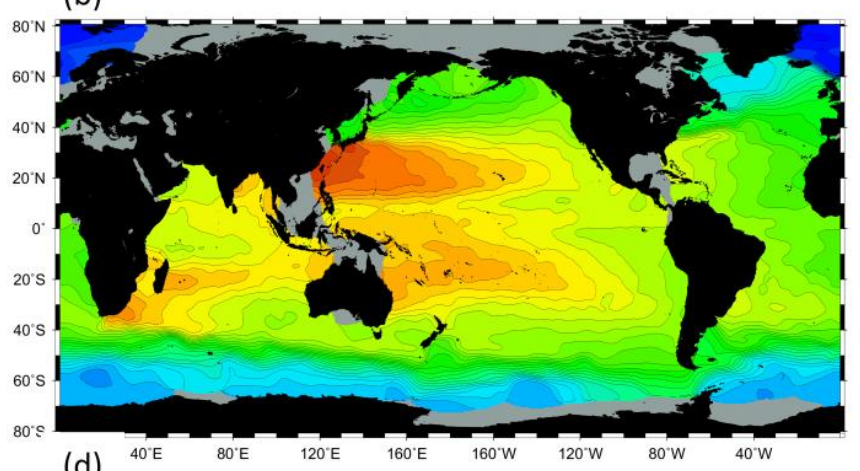

(d)

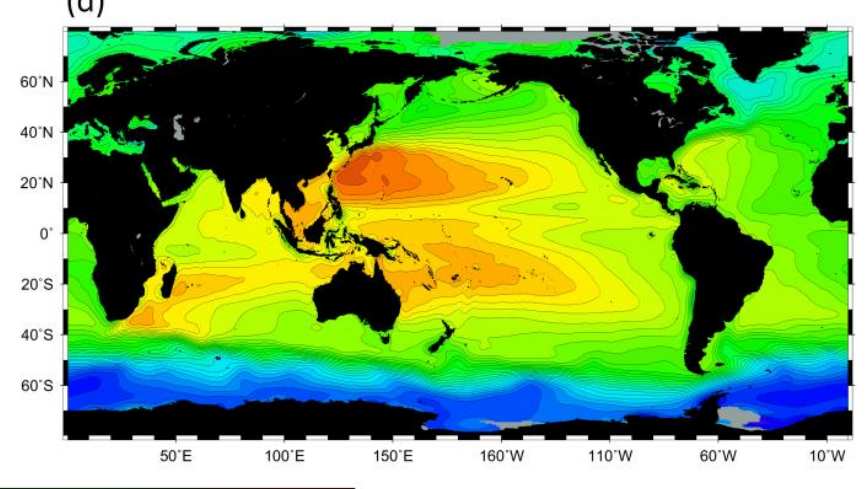

$-240-220-200-180-160-140-120-100-80 \begin{array}{lllllllllllll}1 & -60 & -40 & -20 & 0 & 20 & 40 & 60 & 80 & 100 & 120 & 140\end{array}$

$\mathrm{h}(\mathrm{cm})$

Fig. 2. Synthetic estimates of the MDT unfiltered (a) and filtered at $500 \mathrm{~km}$ (b). Direct MDT computed from MSS CLS01 and EIGEN-GL05S filtered at $133 \mathrm{~km}$ (c) and filtered at $500 \mathrm{~km}(\mathbf{d})$.

at $500 \mathrm{~km}$ resolution at mid and low latitudes is striking, with a $\mathrm{RMS}_{2}$ difference of $5.3 \mathrm{~cm}$ for latitudes ranging between $40^{\circ} \mathrm{S}$ and $40^{\circ} \mathrm{N}$. Strongest discrepancies are obtained at high latitudes where the deep flow corrections applied to the dynamic heights may not be sufficiently known. In the following, RMS height differences will be given only for the $\left[40^{\circ} \mathrm{S}\right.$, $40^{\circ} \mathrm{N}$ ] latitude range, although the RMS velocity differences correspond to the full latitudinal band $\left[90^{\circ} \mathrm{S}, 90^{\circ} \mathrm{N}\right]$.

To illustrate the role of the omission errors we applied the Gaussian filter to the direct MDT using 7 different resolution scales $r_{c}(133,200,300,400,500,700$ and $1000 \mathrm{~km})$ and compared the resulting MDT and the Geostrophic velocities derived from it to the synthetic values, both with $\left(\mathrm{RMS}_{2}\right)$ and without $\left(\mathrm{RMS}_{1}\right)$ similar filtering, Fig. 3.

The main results are as follows:

- At scales shorter than $300 \mathrm{~km}$, the $\mathrm{RMS}_{1}$ values are dominated by the geoid commission and omission errors while $\mathrm{RMS}_{2}$ values are dominated by the geoid commission errors.

- An optimal filtering length of $300 \mathrm{~km}$ is found where $\mathrm{RMS}_{1}$ is a minimum. At scales greater than $300 \mathrm{~km}$ the $\mathrm{RMS}_{1}$ values are dominated by the MDT scales contained in the synthetic heights but not in the direct MDT from which they have been removed by the increased filtering (resulting in increasing $\mathrm{RMS}_{1}$ values).

- The $\mathrm{RMS}_{2}$ values decrease rapidly with increasing filtering length. This shows that the long wavelengths of the direct and synthetic estimates are highly consistent (less than $5 \mathrm{~cm}$ RMS and $5 \mathrm{~cm} \mathrm{~s}^{-1}$ RMS at scales larger than $500 \mathrm{~km}$ ).

In-situ measurements of the ocean dynamic height and velocity are therefore very useful;

1. to evaluate the level of accuracy of different geoid models for deriving the direct MDT,

2. to identify the filtering length necessary to achieve the best consistency between the direct MDT and observations. In the case above it is around $300 \mathrm{~km}$,

3. potentially to make up for the lack of short spatial scales in the direct MDT by combining the synthetic and direct MDTs into a single product.

Methods have been developed that combine the large scale information from direct GRACE-based MDT with the shortest scales contained in the synthetic estimates (Niiler et al., 2003; Maximenko et al., 2005, 2009; Rio and Hernandez, 

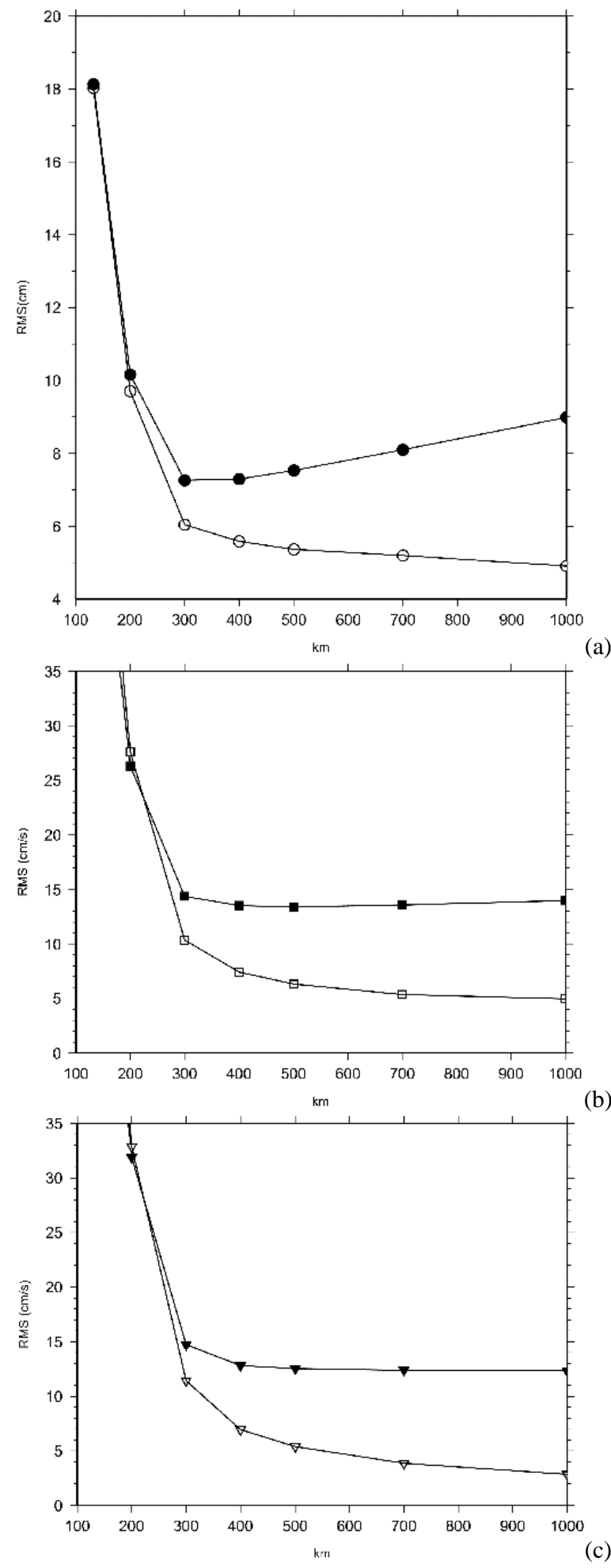

Fig. 3. RMS differences between synthetic and direct MDT estimates as a function of filtering length. Black symbols: only the direct MDT quantities are filtered $\left(\mathrm{RMS}_{1}\right)$. White symbols: both the direct and the synthetic estimates are filtered at the same resolution $\left(\mathrm{RMS}_{2}\right)$. (a) Height RMS differences. (b) Zonal Geostrophic velocity RMS differences. (c) Meridional Geostrophic velocity RMS differences.
2004; Rio et al., 2005). These alternative products have then been used for altimetry assimilation into ocean forecasting systems as described in Sect. 5. Such methods will therefore be very relevant and useful to evaluate the accuracy of the GOCE geoid and complete the GOCE based MDT with shorter scale information where needed.

\subsection{Comparison of different MDT solutions}

Bingham and Haines (2006) have introduced an approach to estimating errors on oceanographic MDTs based on assimilation of hydrographic data into ocean circulation models. They suggested that multiple model dynamic topographies could be used to generate a combined "CMDT" over a region, with the spread of model results giving some measure of uncertainty in this combined product. This idea has been used in other areas of weather and climate modeling, where it has been shown that such combined multi-model ensemble products often do better than even the best single model used alone Palmer et al. (2005), essentially because some of the model bias errors are found to cancel each other. Bingham and Haines (2006) had access to eight different MDTs over the Northern North Atlantic and the Greenland and Norwegian seas, all of which used hydrographic data assimilation to ensure that the models were tied to observations. The models showed a remarkable degree of MDT agreement, and the error estimated from the spread was then used for a further combination of the CMDT with altimeter, geoid, and in situ gravity data over the GOCINA project region in the NE Atlantic, Hipkin and Hunegnaw (2006), Hunegnaw et al. (2009). Vossepoel (2007) have subsequently extended this approach to look at the agreement and spread of model MDTs on more global scales.

These approaches provide independent estimates of the MDT that can be used to compare and judge any new GOCE based geoid and MDT data. Bingham and Haines (2006) presented the information from many MDTs on a Taylor (2001) diagram (their Fig. 3). This figure includes model based MDTs as well as altimeter-geoid based MDTs and surface drifter based MDTs, all for the same region of the North Atlantic. This gives an excellent way of summarizing the degree of agreement between the fields. To do this all the fields were reduced to the same spatial resolution in order to give them all the same omission error on sub-grid point scales. These methods will also be valuable for assessing new MDT results from GOCE.

\subsection{Use of GOCE geoid covariance error}

Any mean dynamic topography estimate based on in situ ocean observational data suffers difficulties from the nonuniform, and often sparse and incomplete, sampling of the ocean in space and time, and it is easy to alias smallscale, high-frequency data into the mean. Conversely ocean model simulations of dynamic topography, while having the 
advantage of being complete in space and time, suffer from biases in the ocean models, some of which are known (e.g. western boundary current paths) and some are not. Alternatively hydrographic data are now routinely assimilated into ocean models, thus allowing the models to interpolate the data in space and time to give a uniformly consistent mean dynamic topography, as in the topographies analysed by Bingham and Haines (2006). However all of these problems make it hard to put appropriate errors on dynamic topography estimates based on oceanographic data. Recent GRACE products are starting to include error covariance information, e.g. the ITG GRACE2010 Bonn product, however these are too recent to have been applied in assimilation calculations. The new GOCE geoid data will provide covariance error estimates as part of the standard products and together with the careful treatment of the altimetric errors, these should prove particularly valuable for assimilating the information into models. The following sections show that work has been underway to include geoid data with its own separate error information.

\section{Assimilation of MDT and altimetric SLA into ocean models}

Time evolving ocean models represent the absolute dynamic topography (ADT) at any given time but the separation into MDT and SLA to allow these to be separately constrained for assimilation purposes is problematic and will depend how the models are being used. There are two possible approaches to assimilating the geoid in the form of a MDT into ocean circulation models. If a long window 4-D Variational (4-DVar) approach is used then the MDT information can be imposed as a separate cost function constraint, as in the ECCO approach (Stammer et al., 2007). There are advantages to this approach, for example the geoid/MDT cost function term can be defined in the natural spherical harmonic space to the required degree and order. The problems with this approach are the general problems of long-window 4-DVar; it is expensive and difficult to apply to high resolution ocean models that are normally used for altimeter SLA assimilation.

The other approach is to combine the geoid-derived MDT with altimetric sea level anomaly data to form the ADT, and to assimilate this in a sequential data assimilation scheme. Many groups have tried this, either without accounting for possible errors in the MDT or by simply increasing the SLA error variance to account for MDT errors. To do this properly it is important to recognize the properties of the different errors in the components of the ADT (Dobricic, 2005). Lea et al. (2008) use a Bayesian approach to derive a bias description of the sea level errors, following work of Drecourt et al. (2006), to introduce the geoid/MDT assimilation. They begin with a variational cost function similar to Stammer et al. (2007), but now including biases, and solve sequentially as a 3-DVar problem. That is;

$$
\begin{aligned}
J & =(\boldsymbol{y}-H(\boldsymbol{x}+\boldsymbol{b}))^{T} R^{-1}(\boldsymbol{y}-H(\boldsymbol{x}+\boldsymbol{b})) \\
& +\left(\boldsymbol{x}-\boldsymbol{x}^{\mathrm{f}}+\boldsymbol{c}\right)^{T} B^{-1}\left(\boldsymbol{x}-\boldsymbol{x}^{\mathrm{f}}+\boldsymbol{c}\right) \\
& +\left(\boldsymbol{b}^{o}-\boldsymbol{b}\right)^{T} T^{-1}\left(\boldsymbol{b}^{o}-\boldsymbol{b}\right) \\
& +\left(\boldsymbol{b}-\boldsymbol{b}^{\mathrm{f}}\right)^{T} O^{-1}\left(\boldsymbol{b}-\boldsymbol{b}^{\mathrm{f}}\right) \\
& +\left(\boldsymbol{c}-\boldsymbol{c}^{\mathrm{f}}\right)^{T} P^{-1}\left(\boldsymbol{c}-\boldsymbol{c}^{\mathrm{f}}\right),
\end{aligned}
$$

which is minimized with respect to $\boldsymbol{x}$, the model state vector, $\boldsymbol{b}$ the observation bias vector (i.e. the current estimate of the MDT error on the model grid), and $c$ the model bias vector. Here $\boldsymbol{y}$ is the observation vector (the altimetric SLA) and $H$ is the observation operator, with superscript $\mathrm{f}$ indicating model forecast or first guess estimates. There are five covariances to specify; $B$ the model background error covariance, $R$ the SLA observation error covariance, $T$ the MDT observation error covariance, $O$ the MDT forecast bias error covariance and $P$ the model forecast bias error covariance.

Minimizing the cost Eq. (4) with respect to $\boldsymbol{x}, \boldsymbol{b}, \boldsymbol{c}$, yields a model ADT analysis

$\boldsymbol{x}^{a}=\left(\boldsymbol{x}^{\mathrm{f}}-\boldsymbol{c}^{\mathrm{f}}\right)+K_{1}\left\{\boldsymbol{y}-H \tilde{\boldsymbol{b}}^{\mathrm{f}}-H\left(\boldsymbol{x}^{\mathrm{f}}-\boldsymbol{c}^{\mathrm{f}}\right)\right\}$
$K_{1}=(B+P) H^{T}\left\{H(B+P+L T) H^{T}+R\right\}^{-1}$

where a rectified MDT forecast bias, $\tilde{\boldsymbol{b}}^{\mathrm{f}}$, is given by

$\tilde{b}^{\mathrm{f}}=L \boldsymbol{b}^{o}+(I-L) \boldsymbol{b}^{\mathrm{f}}$

$L=O(T+O)^{-1}$

The analysis MDT bias is given by,

$$
\begin{aligned}
& \boldsymbol{b}^{a}=\tilde{\boldsymbol{b}}^{\mathrm{f}}+F\left\{\boldsymbol{y}-H \tilde{\boldsymbol{b}}^{\mathrm{f}}-H\left(\boldsymbol{x}^{\mathrm{f}}-\boldsymbol{c}^{\mathrm{f}}\right)\right\} \\
& F=L T H^{T}\left\{H(B+P+L T) H^{T}+R\right\}^{-1}
\end{aligned}
$$

and the analysis model bias by,

$\boldsymbol{c}^{a}=\boldsymbol{c}^{\mathrm{f}}-G\left\{\boldsymbol{y}-H \tilde{\boldsymbol{b}}^{\mathrm{f}}-H\left(\boldsymbol{x}^{\mathrm{f}}-\boldsymbol{c}^{\mathrm{f}}\right)\right\}$

$G=P H^{T}\left\{H(B+P+L T) H^{T}+R\right\}^{-1}$

The analysis Eqs. (5), (7) and (8) use different gains to split the sea level misfits $\left\{\boldsymbol{y}-H \tilde{\boldsymbol{b}}^{\mathrm{f}}-H\left(\boldsymbol{x}^{\mathrm{f}}-\boldsymbol{c}^{\mathrm{f}}\right)\right\}$ into different components. It is critical to have spatially differing error covariances in order to make this separation. In addition Lea et al. (2008) use different models for the time evolution of $\boldsymbol{x}$, $\boldsymbol{b}$, and $\boldsymbol{c}$ to help separate the sea level misfit components;

$\boldsymbol{x}_{k+1}^{\mathrm{f}}=M\left(\boldsymbol{x}_{k}^{a}\right)$

$\boldsymbol{b}_{k+1}^{\mathrm{f}}=\boldsymbol{b}_{k}^{a}$

$c_{k+1}^{\mathrm{f}}=\beta c_{k}^{a}$

Equation (9a) expresses the time evolving numerical ocean model producing an ocean state forecast. For the MDT bias (Eq. 9b) they assume persistence of the previous analysis, because the MDT is not expected to change in time. In the case of model bias (Eq. 9c) some time variation is expected so the model bias has a decay factor $\beta$ from the previous analysis estimate. 


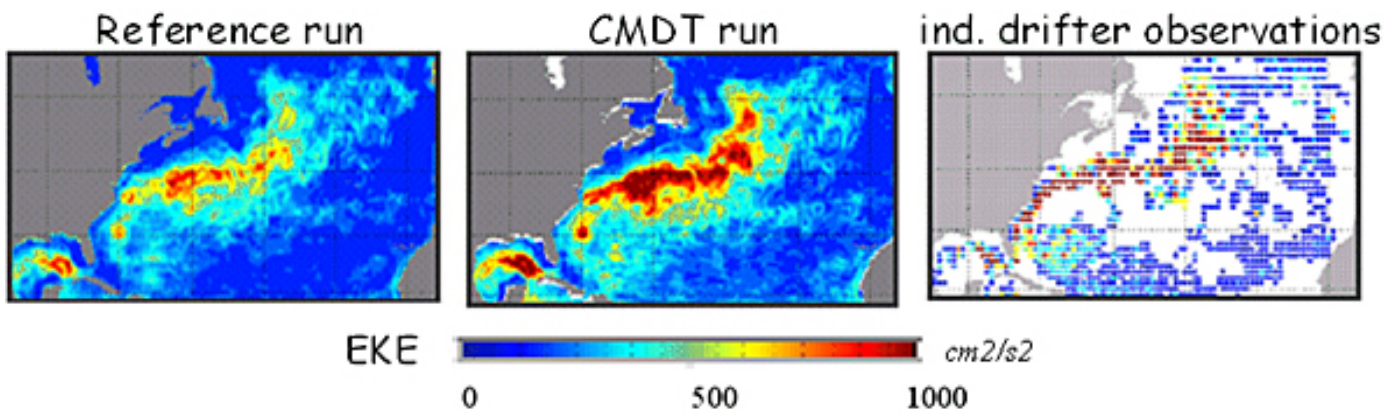

Fig. 4. Mercator 6 months EKE in the Gulfstream area computed from the reference run (left), the run using an observed CMDT (middle) and from independent drifter observations (right).

The ESA GOCE mission is now starting to provide error covariances that can be used for the first time to correctly specify the MDT covariance information (see Sect. 3.3) that is needed in either of the above assimilation approaches. The next section looks at the readiness of some operational data assimilation systems to make use of new satellite geoid data.

\section{Impact of MDT assimilation in operational forecasting systems}

Several data assimilation systems are now operating in $\mathrm{Eu}-$ rope as part of the implementation of the Global Monitoring for Environment and Security (GMES) Marine Core Service project MyOcean (Bahurel et al., 2009). These systems are all assimilating satellite altimeter sea level anomalies (SLA) and could be greatly improved with the new geoid and MDT delivered from GOCE. In the following we report on preliminary impact assessment simulation studies using the MERCATOR (France), FOAM (UK) and TOPAZ (Norway) operational systems. Not all assimilation systems currently seek to impose external MDT information, e.g. at ECMWF and at BLUELINK (Oke et al., 2008) in Australia, they use a model generated MDT for the assimilation of altimeter anomalies and further experimentation would be needed to assimilate an external MDT.

An important issue to consider before assimilating any new MDT into an ocean model (i.e. different from the model mean) is the consistency between the mean, global spatial average of the new MDT and the model. Since only the MDT gradients are dynamically meaningful in driving ocean currents, if necessary the new MDT can be adjusted (adding a constant offset) to the mean model height. If this step is not taken the adjustments to a new mean sea level may still take place (see example Sect. 5.3) but this adjustment will take time and will depend on how sea level is related to other state variables in the given ocean model.

\subsection{Mercator-France}

At MERCATOR Ocean a twin-experiment comparison of altimeter assimilation results covering 8 months (starting in September 2001) used an observational MDT (CMDT run) and the model's own MDT (Reference run). The study shows the strong impact of the more realistic MDT in getting improved analyses and forecasts.

The experiments use the PSY1v1 MERCATOR operational model based on OPA 8.1 (Madec, 1998). This model assimilates both satellite derived Sea Level Anomaly (SLA) and MDT using the SOFA-assimilation scheme (De Mey and Benkiran, 2002) which follows the Cooper and Haines (1996) method of lifting and lowering stratification to adjust for prescribed sea height changes. The model makes the rigid lid, hydrostatic and Boussinesq approximations and the domain covers the North Atlantic between $20^{\circ} \mathrm{S}$ and $70^{\circ} \mathrm{N}$ with latitude dependent resolution varying between $1 / 3^{\circ}$ (equator) and $1 / 6^{\circ}$ (high latitude).

The Reference MDT is derived from the mean sea surface height from a forced model run (i.e. no assimilation) covering January 1992 to December 1995. This MDT is modified to reduce model mean sea surface height and satellite observed sea surface height mismatches (Greiner and Arnault, 2000) and adjusted by adding Halt $1993-1999-$ Halt $_{1992-1995}$ to account for the use of SLA data (in the assimilation) referenced to (1993-1999) rather than (1992-1995), as in Eq. (1). The new CMDT was computed by Rio et al. (2005) through a combination of in-situ data, altimetry and a geoid model using methods similar to those described in Sect. 3.1. The experiment is initialized from operations on 29 August 2001 and run on to 8 May 2002 ( 8 months) assimilating with the respective MDTs. An adjustment is visible in the CMDT run in the first 2 months and the analysis is based on the last 6 months of the runs.

Figure 4 shows the mean Eddy Kinetic Energy (EKE) for the CMDT run, the reference run, and from observed drifters in the Gulf stream region. The use of the new CMDT enhances eddy activity suggesting that constraining the modeled mean current to be in the correct place, allows the model 
to generate eddies that are more consistent with assimilated sea level anomalies, thereby enhancing EKE. The CMDT run produces a stronger and well defined Gulf Stream (GS) that separates well at Cape Hatteras, and the Mann eddy is clearly visible. Circulation around the Grand Banks and Flemish Cap are better defined with clockwise circulation southward around the Flemish Cap. Offshore from the Flemish Cap, the North Atlantic Current flows towards the northwest. The CMDT run yields better defined currents in this region where the Gulf stream (GS) spreads out and separates into several current branches while north of the GS separation point, the southward recirculation is present in the CMDT run (a feature seen in higher resolution models). In contrast the GS appears more sporadic in the reference run.

Figure 5 shows a cross section at $72^{\circ} \mathrm{W}$ across the Gulf Stream of mean temperature and mean zonal velocities for the two runs. The CMDT provides stronger horizontal temperature gradients down to at least $2000 \mathrm{~m}$, and the velocities appear distributed deeper in the water column. The recirculation feature in the CMDT run is distributed across the entire water column.

Simulated profiles from both model runs are compared to the available 14500 CORIOLIS data base profiles during the 6 months of the analysis. Model temperature fields are interpolated to the observation points $(x, y, z$ and $t)$. Results at each profile location are then depth-binned $(0-100,100$ 500 and $500-1000 \mathrm{~m}$ ). Here only results from the $100-500 \mathrm{~m}$ bins are discussed since this is the depth where the strongest stratification corrections occur. For other depths differences between the CMDT and the reference runs do not change sign, but may change in magnitude. Scatter plots were produced on 22 MERCATOR pre-determined analysis zones of which only the subpolar gyre is shown in Fig. 6. These reveal a general improvement in the CMDT run. Mean bias and standard deviation errors with respect to the observations are clearly decreased.

\subsection{Met Office UK}

At the Met Office the operational oceanography (FOAM) suite assimilates real time or near real time data including satellite sea surface temperature, sea level anomaly (SLA), in-situ temperature and salinity data from e.g. Argo. See Martin et al. (2007) for a more detailed description of FOAM. The along track altimeter SLA data is obtained from Collecte Localisation Satellites (CLS). The altimeter data is assimilated along with the MDT which is derived from model and observational estimates.

The FOAM system has for many years simply inflated the ADT observation errors to account for MDT errors during altimeter assimilation. Recently the observation bias method described in Sect. 4 has been introduced (although the model biases have not yet been implemented operationally) and preliminary results are shown below. The (Rio et al., 2005) MDT was used to assimilate altimeter data into the new
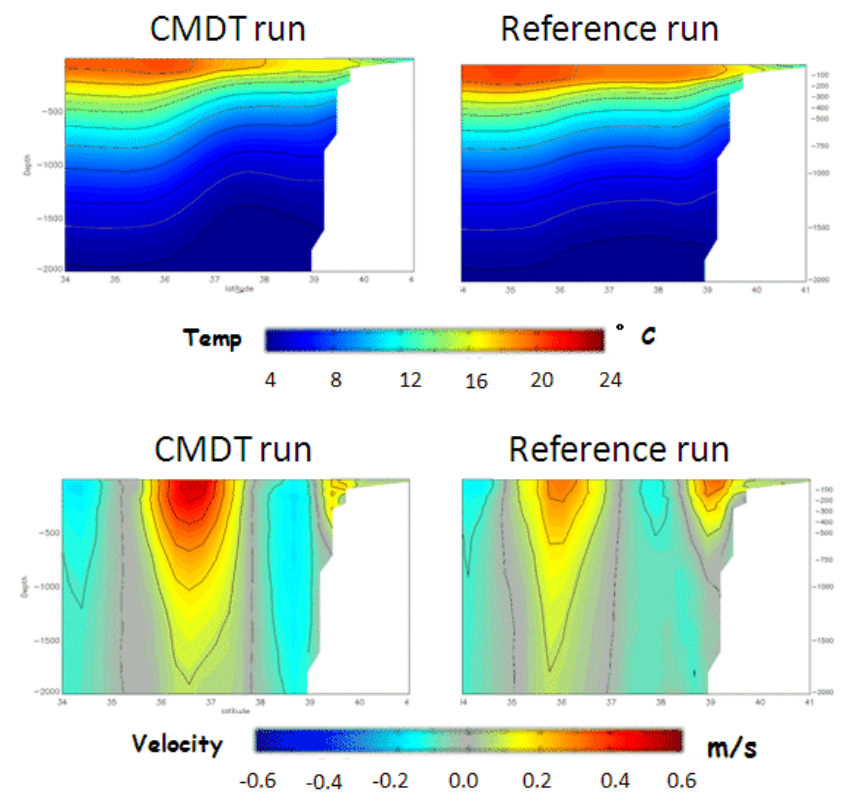

Fig. 5. Cross section of temperature (top) and zonal velocity (bottom) at $72^{\circ} \mathrm{W}$ longitude in the Mercator CMDT run (left) and the reference run (right).

suite of NEMO (Madec, 2008) based operational models (see Fig. 7 which shows the observation bias calculated by the scheme in each of the model domains). The Rio et al. (2005) error amplitudes were increased by a factor of 5 and a correlation scale of $40 \mathrm{~km}$ was chosen to give the Rio MDT error covariance $T$, following Knudsen and Tscherning (2007). The MDT forecast bias error covariance $O$, which controls the change in $\boldsymbol{b}$ at each analysis, was set to $0.01 T$. This forces the bias to change slowly preventing a noisy estimate.

Three hindcast assimilation experiments, performed over a three month period, are compared to assess the impact of altimeter observation bias correction. These runs are identical and assimilate all data types, except that:

- Expt. STD assimilates altimeter data but without observation bias correction.

- Expt. OBS assimilates altimeter data with observation bias correction.

- Expt. CTL does not assimilate altimeter data.

Table 1 shows the RMS innovations which are the observation values minus the model forecast before assimilation (model background) at the observation locations. The innovations use the bias corrected observation and model values where appropriate. The innovation mean can be thought of as representing the remaining unexplained bias in the system.

Altimeter assimilation with altimeter bias correction gives a $2 \mathrm{~cm}$ global reduction in RMS innovations compared to the hindcast without bias correction. This is the same reduction 
CMDT run

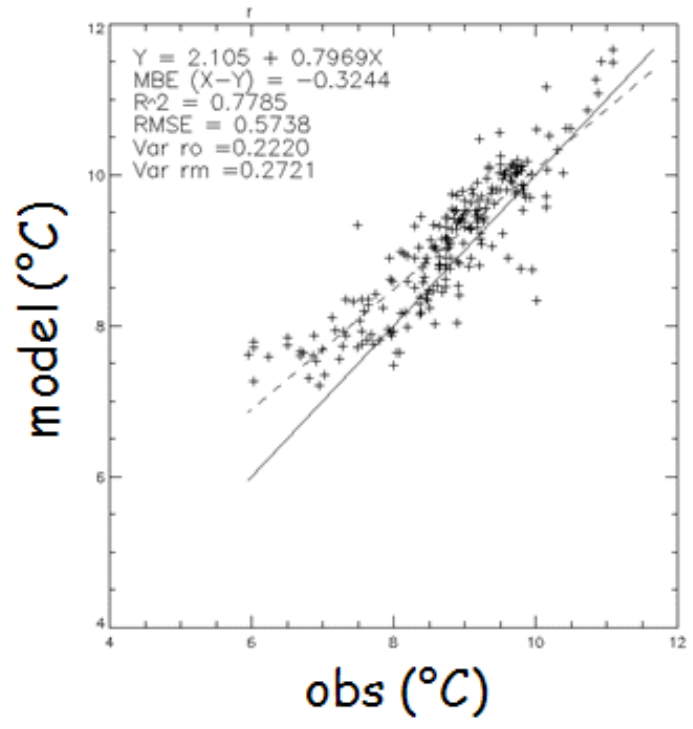

Reference run

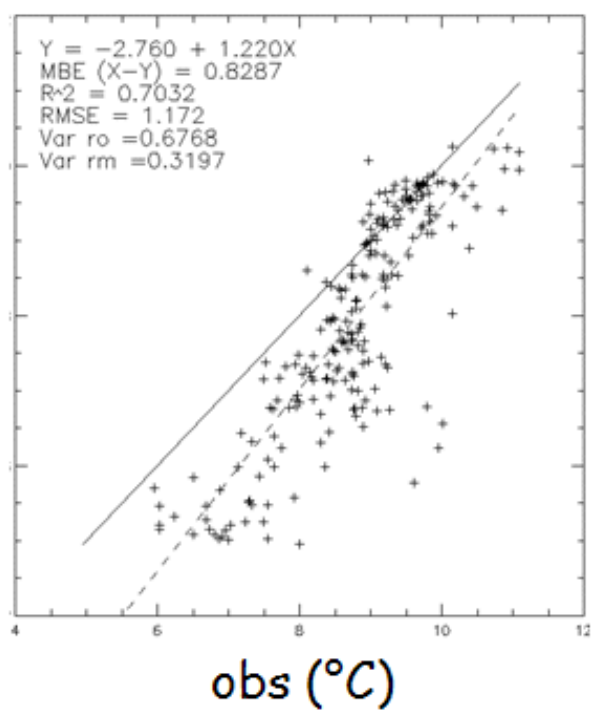

Fig. 6. Scatter plot of Mercator model temperatures versus observational profile temperatures between 100 and $500 \mathrm{~m}$ for the CMDT run (left) and the reference run (right) in the subpolar gyre.

in RMS as that achieved by assimilating altimeter data compared to not doing so at all! Some regions show greater improvements for example the Southern Ocean where bias correction reduces the RMS error by $4 \mathrm{~cm}$.

Improving the altimeter assimilation with bias correction also has a positive impact on other aspects of the model results. This can be seen, for example, in the temperature profile innovation statistics, which slightly improve using the modified MDT, showing a more consistent reproduction of the upper ocean steric heights, So it is a strong result that assimilating bias corrected altimeter data gives a lower RMS of $0.61{ }^{\circ} \mathrm{C}$ compared to assimilating without a bias correction $\left(0.63^{\circ} \mathrm{C}\right)$, or not assimilating altimeter data $\left(0.64^{\circ} \mathrm{C}\right)$. In the tropical Atlantic assimilating altimeter data without bias correction appears to do serious damage to the temperature profiles, giving $0.72^{\circ} \mathrm{C}$ RMS error, where no altimeter assimilation gives $0.60^{\circ} \mathrm{C}$ RMS error. However, assimilating bias corrected data improves this result with a $0.57^{\circ} \mathrm{C}$ RMS error. Noticeable improvements in the currents are also seen.

The Met Office has implemented the observation bias correction scheme in the new operational system based on NEMO, and the model bias component also described in Sect. 4 is currently being tested for operational use. The GOCE based MDT and MDT errors will then be available to replace the (Rio et al., 2005) MDT used in this assimilation configuration when they become available.

\subsection{TOPAZ Norway}

The TOPAZ operational oceanography suite (Bertino and Lisæter, 2008) was used to perform a MDT assimilation experiment. The TOPAZ system uses the HYCOM v1.3 ocean model configuration covering the whole Atlantic and Arctic Oceans (see Fig. 8) with a resolution between $18 \mathrm{~km}$ and $36 \mathrm{~km}$ (1/4 to $1 / 3$ degree) and 22 hybrid vertical layers. An Ensemble Kalman Filter (EnKF) was run with 100 members, assimilating (MDT + SLA) maps, SSTs and sea-ice concentrations. To test the ability to change MDT information an external MDT was taken from a global 1/4 deg reanalysis, of the OCCAM model (Fox and Haines, 2003). It was noted only after the experiment that this external MDT had an area mean offset from the free running HYCOM model dynamic topography of about $30 \mathrm{~cm}$. Although this can be expected when comparing MDTs from different models covering different areas, the fact that this mismatch was not corrected before assimilation (as in the other systems) leads to some interesting results.

The experiment showed that the EnKF assimilation adjustments to the large MDT offset are regionally dependent (Fig. 8). The Equatorial region (EQ), defined between $22.5^{\circ} \mathrm{S}$ and $22.5^{\circ} \mathrm{N}$, adjusts the SSH faster, within two months, while the mid- and high latitudes need almost the full year to reduce the large initial bias. The convergence is even slower in the Southern part of the domain, but no data were assimilated in the first 50 rows of this domain $(1000 \mathrm{~km}$ from the Southern model boundary). The input statistics of the three EnKF prior error terms (initial error, model error and measurement errors) have uniform values over the model domain, but the ensemble propagation in the model develops flow-dependent - and thus regionally different - forecast error covariances. This means that the differences in the adjustment of the MDT are linked to the different physical processes predominantly acting in the tropics and mid-latitudes. 

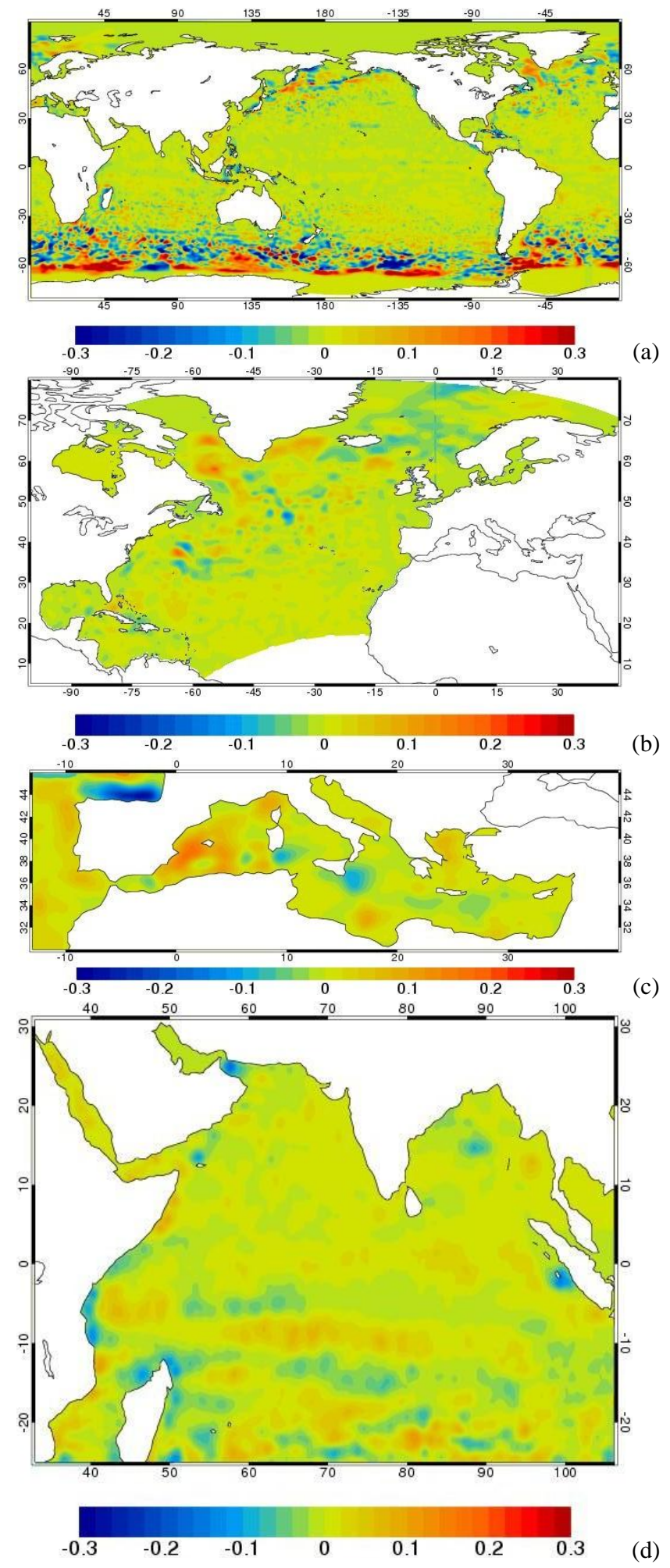

Fig. 7. Observation bias, in $\mathrm{m}$ for the Met Office NEMO operational models (19 August 2009). (a) 1/4 degree global, (b) 1/12 North Atlantic, (c) 1/12 degree Mediterranean (d) 1/12 degree Indian Ocean.
Table 1. Comparison of SSH RMS and mean innovations for global model hindcasts averaged in various regions and over the period 1 February 2008 to 30 April 2008 from the Met Office FOAM system.

\begin{tabular}{|c|c|c|c|}
\hline & $\begin{array}{l}\text { STD: } \\
\text { NoAltBias } \\
\text { RMS (mean) } \mathrm{m}^{-1}\end{array}$ & $\begin{array}{l}\text { OBS: } \\
\text { AltBias } \\
\text { RMS (mean) } \mathrm{m}^{-1}\end{array}$ & $\begin{array}{l}\text { CTL: } \\
\text { NoAlt } \\
\text { RMS (mean) } \mathrm{m}^{-1}\end{array}$ \\
\hline Global & $0.11(-0.01)$ & $0.09(0.00)$ & $0.13(-0.04)$ \\
\hline Arctic & $0.10(0.01)$ & $0.08(0.01)$ & $0.10(-0.03)$ \\
\hline North Atlantic & $0.10(-0.01)$ & $0.10(-0.01)$ & $0.12(-0.05)$ \\
\hline Tropical & $0.05(-0.00)$ & $0.05(0.00)$ & $0.07(-0.03)$ \\
\hline \multicolumn{4}{|l|}{ Atlantic } \\
\hline South Atlantic & $0.15(0.01)$ & $0.13(0.01)$ & $0.17(-0.01)$ \\
\hline North Pacific & $0.09(-0.01)$ & $0.08(-0.01)$ & $0.13(-0.08)$ \\
\hline Tropical Pacific & $0.06(-0.02)$ & $0.05(-0.02)$ & $0.11(-0.09)$ \\
\hline South Pacific & $0.08(0.01)$ & $0.07(0.01)$ & $0.10(-0.04)$ \\
\hline $\begin{array}{l}\text { Tropical Indian } \\
\text { Ocean }\end{array}$ & $0.06(-0.02)$ & $0.06(-0.01)$ & $0.09(-0.06)$ \\
\hline $\begin{array}{l}\text { South Indian } \\
\text { Ocean }\end{array}$ & $0.13(0.00)$ & $0.11(0.00)$ & $0.16(-0.04)$ \\
\hline Mediterranean & $0.12(-0.09)$ & $0.11(-0.07)$ & $0.18(-0.15)$ \\
\hline Southern Ocean & $0.15(0.03)$ & $0.11(0.03)$ & $0.16(0.01)$ \\
\hline
\end{tabular}

One possible interpretation lies in the shallower stratification of the Equatorial Atlantic Ocean. Initially the TOPAZ system assumes a $10 \%$ error in the thickness of all isopycnal model layers, while the model error growth continuously feeding the EnKF are applied to surface winds and heat fluxes. In the tropics where the water column is more stratified than at high latitudes, the dynamic height is more sensitive to changes in the stratification and the shallow mixed layer is also more sensitive to variations of surface parameters. This makes it easier for the EnKF to transmit changes of the MDT into an update of the ocean stratification in the tropical regions. In high latitudes it is more demanding to impose the external MDT since the stratification is more barotropic, with deeper mixed layers. The results above are produced in a case of severe bias in the MDT. Nevertheless the results imply that the impact of GOCE data might be expected to be regionally and temporally dependent.

\section{Discussion}

The GOCE satellite was successfully launched in March 2009 and the first data are now available, and have shown some improvements over GRACE data, Bingham et al. (2011). Low levels of solar activity suggest that it should perform even beyond the design specifications. Ocean assimilation results presented here using high resolution MDTs based on GRACE geoids indicate that considerable further changes in ocean model circulation can be expected by assimilating an MDT based on an improved GOCE geoid. The methodologies for assimilation of these data are however still in their infancy and there has been increased activity recently trying to find improved or optimal ways of using these data. We have here reviewed the results and progress 

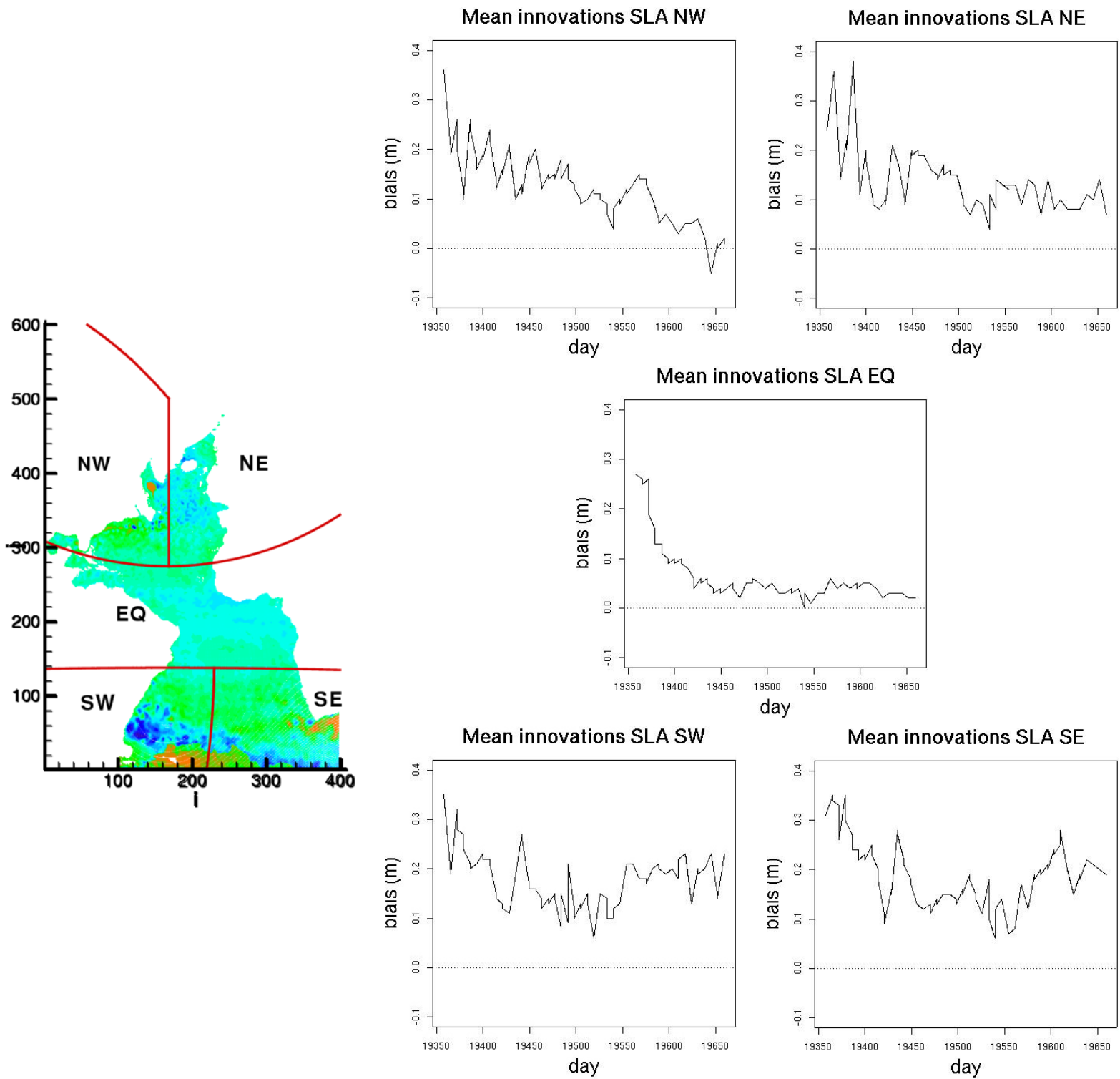

Fig. 8. Decomposition of the TOPAZ model domain with a map of SLA innovations as background (left) and evolution of the mean error in each of the five sub-domain during from January to December 2003 (right).

in this direction at three of the major European Ocean forecasting centres, in France, the UK and Norway. Both Mercator and the UK Met Office systems show clear improvements in the temperature profile errors after assimilating the externally imposed MDTs. The bias system at the Met Office has the additional advantage that it allows the MDT to be adjusted within error bars to give an even closer agreement to independent profile data. The TOPAZ results also show the importance of stratification in the response of models to MDT changes, but all systems show that projection of MDT increments below the surface is effective using similar methods to those used for SLA assimilation. These methods are promising for a positive impact of new GOCE data on operational oceanography but need further development using realistic error measures to obtain the best impacts of geoid information when assimilating into ocean circulation models.

This paper gives an overview of the state of the art at using geoid data for ocean circulation studies and indicates the many pitfalls that can be avoided with care when developing a Mean dynamic topography (MDT) from geodetic information, and then using that MDT to constrain the circulation in an ocean model. It is aimed at both the ocean modelling and altimeter communities to explain the additional information that will be available from GOCE and how it will be obtained, and also for the benefit of the geodetic community, 
to emphasise the challenges of using geoid data to constrain ocean circulation. It is hoped that this will bring the different communities to work together more effectively to get the best out of the new GOCE data that is becoming available.

Acknowledgements. The authors would like to thank the EU for funding the GOCINA integrated project, the GOCINO network program, and ESA for funding the GOCE User Toolbox Study (GUTS) which helped to engineering important collaborations between the geodetic and the ocean modelling communities in the lead up to the GOCE mission.

Edited by: A. Schiller

\section{References}

Bahurel, P., Adragna, F., Bell, M., Jacq, F., Johannessen, J. A., Le Traon, P.-Y., Pinardi, N., and She, J.: MyOCEANA European example of a Post-GODAE initiative, available at: http://www.godae.org/modules/documents/documents/ Proceedings-GFS-2008.pdf, 2009.

Benveniste, J., Knudsen, P., and the GUTS Team: The GOCE User Toolbox, in: Proceedings of the 3rd International GOCE User Workshop, 6-8 November 2006, Frascati, Italy, edited by: Fletcher, K., Noordwijk: European Space Agency, 2007.

Bertino, L. and Lisæter, K. A.: The TOPAZ monitoring and prediction system for the Atlantic and Arctic Oceans, Journal of Operational Oceanography, 1(2), 15-18, 2008.

Bingham, R. J. and Haines, K.: Mean dynamic topography: intercomparison and errors, Philos. T. R. Soc. A, 364, 903-916, 2006.

Bingham, R. J., Haines, K., and Hughes, C. W.: Calculating the Ocean's Mean dynamic topography from a Mean sea surface and a Geoid, J. Atmos. Ocean. Tech., 25, 1808-1822, doi:10.1175/2008JTECHO568.1, 2008.

Bingham, R. J., Knudsen, P., Andersen, O., and Pail, R.: An initial estimate of the North Atlantic steady-state geostrophic circulation from GOCE, Geophys. Res. Lett., 38, L01606, doi:10.1029/2010GL045633, 2011.

Carrère, L. and Lyard, F.: Modelling the barotropic response of the global ocean to atmospheric wind and pressure forcing - comparisons with observations, Geophys. Res. Lett., 30(6), 1275, doi:10.1029/2002GL016473, 2003.

Chambers, D. P., Tamisiea, M. E., Nerem, R. S., and Ries, J. C.: Effects of ice melting on GRACE observations of ocean mass trends, Geophys. Res. Lett., 34, L05610, doi:10.1029/2006GL029171, 2007.

Cooper, M. C. and Haines, K.: Data assimilation with water property conservation, J. Geophys. Res., 101(C1), 1059-1077, 1996.

De Mey, P. and Benkiran, M.: A multivariate reduced-order optimal interpolation method and its application to the Mediterranean basin-scale circulation, in: Ocean Forecasting, Conceptual basis and applications, edtited by: Pinardi, N. and Woods, J. D., Springer-Verlag, Berlin Heidelberg New York, 472 pp., 2002.

Denker, D. and Rapp, R. H.: Geodetic and Oceanographic Results from the Analysis of One Year of Geosat Data, J. Geophys. Res., 95(C8), 13151-13168, 1990.

Dobricic, S.: New mean dynamic topography of the Mediterranean calculated from assimilation system diagnostics, Geophys. Res. Lett., 32, L11606, doi:10.1029/2005GL022518, 2005.
Drecourt, J.-P., Haines, K., and Martin, M. J.: Influence of systematic error correction on the temporal behaviour of an ocean model, J. Geophys. Res., 111, C11020, doi:10.1029/2006JC003513, 2006.

Engelis, T. and Knudsen, P.: Orbit Improvement and Determination of the Oceanic Geoid and Topography from 17 Days of Seasat Data, Manuscr. Geodaet., 14(3), 193-201, 1989.

Fox, A. D and Haines, K.: Interpretation of Water transformations diagnosed from data assimilation, J. Phys. Oceanogr., 33, 485498, 2003.

Greiner, E. and Arnault, S.: Comparing the results of a 4Dvariational assimilation of satellite and in situ data with WOCE CITHER hydrographic measurements in the tropical Atlantic Progress, Oceanography, 47(1), 1-68, doi:10.1016/S00796611(00)00031-8, 2000.

Hernandez, F. and Schaeffer, P.: Altimetric mean sea surfaces and gravity anomaly maps inter-comparisons, Rep. AVI-NT-0115242-CLS, Collect. Location de Satell., Ramonville St Agne, France, 48 pp., 2000.

Hipkin, R. and Hunegnaw, A.: Mean dynamic topography by an iterative combination method, in: Proceedings of the Workshop on GOCINA: Improving Modelling of Ocean Transport and climate Prediction in the North Atlantic Region Using GOCE Gravimetry, edited by: Knudsen, P., Johannessen, J., Gruber, T., Stammer, S., and van Dam, T., Cah. Cent. Eur. Geodyn. Seismol., 25, 11$16,2006$.

Hughes, C. W. and Bingham, R. J.: An Oceanographer's Guide to GOCE and the Geoid, Ocean Sci., 4, 15-29, doi:10.5194/os-415-2008, 2008.

Hunegnaw, A., Siegismund, F., Hipkin, R., and Mork, K. A.: Absolute flow field estimation for the Nordic seas from combined gravimetric, altimetric, and in situ data, J. Geophys. Res., 114, C02022, doi:10.1029/2008JC004797, 2009.

Jayne, S. R.: Circulation of the North Atlantic Ocean from altimetry and the Gravity Recovery and Climate Experiment geoid, J. Geophys. Res., 111, C03005, doi:10.1029/2005JC003128, 2006.

Johannessen, J. A., Balmino, G., Le Provost, C., Rummel, R., Sabadini, R., Sünkel, H., Tscherning, C. C., Visser, P., Woodworth, P., Hughes, C. W., LeGrand, P., Sneeuw, N., Perosanz, F., Aguirre-Martinez, M., Rebhan, H., and Drinkwater, M.: The European Gravity Field and Steady-State Ocean Circulation Explorer Satellite Mission: Impact in Geophysics, Surv. Geophys., 24, 339-386, 2003.

Knudsen, P.: Simultaneous Estimation of the Gravity Field and Sea Surface Topography From Satellite Altimeter Data by Least Squares Collocation, Geophys. J. Int., 104(2), 307-317, 1991.

Knudsen, P.: Estimation of Sea Surface Topography in the Norwegian Sea Using Gravimetry and Geosat Altimetry, B. Geod., 66(1), 27-40, 1992.

Knudsen, P. and the GOCINA Team: Integration of Altimetry and GOCE Geoid For Ocean Modeling: Results From The GOCINA Project, Proc. 3rd International GOCE User Workshop, Frascati, Italy, ESA Publications SP-627, ISBN-92-9092-938-3, 2007.

Knudsen, P. and Tscherning, C. C.: Error Characteristics of Dynamic Topography Models Derived from Altimetry and GOCE Gravimetry, IAG symposia, Springer Verlag, Vol. 130, ISBN103-540-49349-5, 11-16, 2007.

Knudsen, P., Andersen, O. B., Forsberg, R., Föh, H. P., Olesen, A. V., Vest, A. L., Solheim, D., Omang, O. D., Hipkin, R., 
Hunegnaw, A., Haines, K., Bingham, R., Drecourt, J.-P., Johannessen, J. A., Drange, H., Siegismund, F., Hernandez, F., Larnicol, G., Rio, M.-H., and Schaeffer, P.: GOCINA - Geoid and Ocean Circulation in the North Atlantic - Final Report, Danish National Space Center, Technical Report, No. 5., 2006a.

Knudsen, P., Johannessen, J. A., Gruber, T., Stammer, D., van Dam, T. (Eds.): GOCINA: Improving modelling of ocean transport and climate prediction in the North Atlantic region using GOCE gravimetry, Proceeding from the GOCINA Workshop, Luxembourg, 2005, Cahiers du Centre European de Geodynamique et de Seismologie, Vol. 25, ISBN-2-9599804-2-5, 199 pp., 2006 b.

Knudsen, P., Andersen, O. B., Forsberg, R., Föh, H. P., Olesen, A. V., Vest, A. L., Solheim, D., Omang, O. D., Hipkin, R., Hunegnaw, A., Haines, K., Bingham, R., Drecourt, J.-P., Johannessen, J. A., Drange, H., Siegismund, F., Hernandez, F., Larnicol, G., Rio, M.-H., and Schaeffer, P.: Combining altimetric/gravimetric and ocean model mean dynamic topography models in the GOCINA region, IAG symposia, Springer Verlag, Vol. 130, ISBN-103-540-49349-5, 3-10, 2007a.

Knudsen, P., Andersen, O. B., and Andersson, T. B.: Optimal filtering of mean dynamic topography models, Proc. 3rd International GOCE User Workshop, Francati, Italy, ESA Publications SP-627, ISBN-92-9092-938-3, 2007b.

Lea, D. J., Drecourt, J.-P., Haines, K., and Martin, M. J.: Ocean altimeter assimilation with observational- and model-bias correction, Q. J. Roy. Meteor. Soc., 134, 1761-1774, 2008.

Levitus, S. and Boyer, T. P.: World ocean atlas 1994, vol. 4, Temperature NOAA Atlas NESDIS 4, National Ocean and Atmosphere Administration USA, 117 pp., 1994.

Madec, G.: NEMO ocean engine, Note du Pole de modélisation, Institut Pierre-Simon Laplace (IPSL), France, 27, 1288-1619, 2008.

Marsh, J. G., Koblinsky, C. J., Lerch, F. J., Klosko, S. M., Martin, T. V., Robbins, J. W., Williamson, R. G., and Patel, G. B.: Dymanic Sea Surface Topography, Gravity, and Improved Orbit Accuracies from the Direct Evaluation of Seasat Altimeter Data, J. Geophys. Res., 95(C8), 13129-13150, 1990.

Martin M. J., Hines, A., and Bell, M. J.: Data assimilation in the FOAM operational short-range ocean forecasting system: A description of the scheme and its impact, Q. J. Roy. Meteor. Soc., 133, 981-994, 2007.

Mazzega, P. and Houry, S.: An experiment to invert Seasat altimetry for the Mediterranean and Black Sea mean surface. Geophys. J., 96, 259-272, 1989.

Maximenko, N. A. and Niiler, P. P.: Hybrid decade-mean global sea level with mesoscale resolution, in: Recent Advances in Marine Science and Technology, edited by: Saxena, N., PACON International, 55-59, 2005.

Maximenko, N., Niiler, P., Rio, M.-H., Melnichenko, O., Centurioni, L., Chambers, D., Zlotnicki, V., and Galperin, B.: Mean dynamic topography of the ocean derived from satellite and drifting buoy data using three different techniques, J. Atmos. Ocean. Tech., 26(9), 1910-1919, 2009.
Nerem, R. S., Tapley, B. D., and Shum, C. K.: Determination of the Ocean Circulation Using Geosat Altimetry, J. Geophys. Res., 95(C3), 3163-3179, 1990.

Niiler, P., Maximenko, N. A., and McWilliams, J. C.: Dynamically balanced absolute sea level of the global ocean derived from near-surface velocity observations, Geophys. Res. Lett., 30(22), 2164-2167, 2003.

Oke, P. R., Brassington, G. B., Griffin, D. A., and Schiller, A.: The Bluelink ocean data assimilation system (BODAS), Ocean Model., 21, 46-70, 2008.

Palmer, T. N., Doblas-Reyes, F. J., Hagedorn, R., and Weisheimer, A.: Probabilistic prediction of climate using multi-model ensembles: from basics to applications, Philos. T. R. Soc. B, 360, 19911998, doi:10.1098/rstb.2005.1750, 2005.

Rio, M.-H. and Hernandez, F.: A Mean Dynamic Topography computed over The world ocean from altimetry, in-situ measurements and a geoid model, J. Geophys. Res., 109, C12032, doi:10.1029/2003JC002226, 2004.

Rio, M. H., Shaeffer, P., Hernandez, F., and Lemoine, J. M.: The estimation of the ocean Mean Dynamic Topography through the combination of altimetric data, in situ measurements and GRACE geoid: From global to regional studies, in: Proceeding from the GOCINA Workshop, Luxembourg, 2005, Cahiers du Centre European de Geodynamique et de Seismologie, Vol. 25, ISBN-2-9599804-2-5, 171-176, 2005.

Stammer D., Kohl, A., and Wunsch, C.: Impact of Accurate Geoid Fields on Estimates of the Ocean Circulation, J. Atmos. Ocean. Tech., 24, 1464-1478, 2007.

Taylor, K. E.: Summarizing multiple aspects of model performance in a single diagram, J. Geophys. Res., 106(D7), 7183-7192, doi:10.1029/2000JD900719, 2001.

Vianna, M. L. and Menezes, V. V.: Mean mesoscale global ocean currents from geodetic pre-GOCE MDTs with a synthesis of the North Pacific circulation, J. Geophys. Res., 115, C02016, doi:10.1029/2009JC005494, 2010.

Vossepoel, F. C.: Uncertainties in the mean ocean dynamic topography before the launch of the Gravity Field and Steady-State Ocean Circulation Explorer (GOCE), J. Geophys. Res., 112, C05010, doi:10.1029/2006JC003891, 2007.

Wagner, C. A.: Accuracy Estimates of Geoid and Ocean Topography Recovered Jointly From Satellite Altimetry, J. Geophys. Res., 91(B1), 453-461, 1986.

Willis, J. K., Chambers, D. P., and Nerem, R. S.: Assessing the globally averaged sea level budget on seasonal to interannual timescales, J. Geophys. Res., 113, C06015, doi:10.1029/2007JC004517, 2008.

Wunsch, C. and Zlotnicki, V.: The accuracy of altimetric surfaces, Geophys. J. Roy. Astr. S., 78, 795-808, 1984. 